\title{
Pay review in an election year
}

In this year's report from the Doctors' and Dentists' Review Body (page 1662) doctors have been recommended an average pay increase of $6^{\circ} \%{ }^{1}$ Many doctors in training will get more, and the report strongly urges restoration of the abatement, now worth $2.7 \%$ of the total pay bill, that the government imposed on the profession's awards in 1981 and 1982 to keep them to what it claimed the country could afford to pay. The fact that Mrs Margaret Thatcher's administration has accepted the $6 \%$ recommendation and agreed that the $2 \cdot 7 \%$ should be paid -but not backdated-from 1 January 1984 suggests that the review body does, as the $B M \mathcal{F}$ argued last year, ${ }^{2}$ have value. Perhaps the Prime Minister has also tacitly acknowledged that as a result of the 33 months' abatement of pay by the end of this year doctors will have contributed around $£ 90$ million in "lost" income towards reducing inflation.

Sir Robert Clarke and his colleagues on the review body (page 1664) have not resigned. Though presumably unhappy with this third episode of government interference, they acknowledge, so the British Medical Association has been told, that the government, by paying in full the appropriate rates (an average $8.7 \%$ above the $1982-3$ remuneration) with effect from January 1984, has accepted the review body's conclusions, made after taking into account the country's economic circumstances. It means that the 1984 review will start from the intended baseline. Naturally the BMA deplores the government's decision, which $\mathrm{Mr}$ Norman Fowler explained to leaders of the association on 12 May in what could well be his last meeting with them as Secretary of State for Social Services. On a more helpful note at that meeting he reassured them that the extra money needed to fund the award over and above that included within the 1983-4 cash limits will be wholly provided by the government to health authorities. Doctors and district health authorities will expect the incoming Secretary of State, of whatever party, to honour this pledge.

The BMA's joint evidence committee submitted its usual detailed evidence for the pay review ( $p$ 1669) and there will be disappointment that the review body has not accepted the arguments that the profession's remuneration needed to rise by about $20 \%$ to restore its relative position to that established in the 1980 report. In explaining its conclusions the review body argues that "the relative position of doctors and dentists in the earnings hierarchy ... should [not] necessarily be a fixed one...." Furthermore, the increasing number of doctors in the NHS and the supply of good quality recruits to medical schools was clearly influential evidence. No doubt the prolonged and bitter dispute over pay in the Health Service which ended more or less on the government's terms ${ }^{3}(12.3 \%$ for nurses and $10.5 \%$ for most other staff, the increases to be spread over two years) was also a factor in the review body's deliberations.

Perhaps recalling Sir Harold Wilson's election troubles with the doctors' 1970 pay review, ${ }^{4}$ this cabinet presumably wished to avoid making the 1983 award an election issue ( $p$ 1660). By adjusting it in such a way as to bring it within the limits of present public sector pay settlement levels yet leaving doctors $\mathbb{\Phi}$ with their recommended levels of pay by the end of the pay year the cabinet may well be successful. Furthermore, had the government interfered more drastically than it has with the $\overrightarrow{\vec{D}}$ recommendations, that would surely have jeopardised the already troubled discussions on setting up the proposed nurses' review body, ${ }^{5}$ a crucial element in the government's pay strategy for the NHS. ${ }^{6}$

The many junior doctors affected will be pleased at the improved rewards for their long hours of work, dealt with in some detail in the report (page 1666). The Hospital Junior Staff Committee will not, however, be pleased at the review body's return to its theme that a professional salary is more appropriate for doctors than out of hours payments. The confused position over doctors' workload remains unresolved, with the review body concluding that there is no firm evidence for it having risen: the BMA will have to continue the so far unrewarding search for some convincing evidence that it has. General practitioners will probably be mystified about why their (average) indirectly reimbursed practice expenses have risen by a trivial $£ 30$ over last year's recommended figure of $ᄋ$ $£ 9260$ when despite a sharply falling inflation rate costs of $N$ running a practice have risen. The reasoning behind this seeming paradox are given at page 1665 .

The profession's hard working negotiators deserve the profession's thanks, though they will be disappointed that not all their arguments have prevailed. As realistic medicopoliticians, however, the negotiators will have compared the award with other public sector settlements and assessed the political uncertainties of a general election. Not surprisingly, therefore, discussions have already started with the Health Departments to implement the award, which will result in an average increase for NHS doctors of $6.8 \%$ for the whole pay year $(8.1 \%$ if the increased rates for junior doctors' units of medical time are included). Few doctors are likely to object to this prudent step, whatever reservations they may have on particular parts of the review body's Thirteenth Report.

\footnotetext{
Review Body on Doctors' and Dentists' remuneration. Thirteenth report 1983. Cmnd 8878. London: HMSO, 1983.

2 Anonymous. How valuable is the review body? Br Med $\mathcal{F} 1982 ; 284$ : 1429-50.

3 Macintyre D. NHS dispute collapses in 90 minutes of talks. The Times 1982;Dec 16:1.

4 Anonymous. Independence at stake. $\mathrm{Br} \mathrm{Med} \mathcal{F}$ 1970;2:615-6.

${ }^{5}$ Anonymous. Review body for nurses and allied staff. Br Med $\mathcal{F} 1983 ; 286$ 1370.

${ }^{6}$ Dyson R. Pay noose for National Health Service? Br Med $\mathcal{F} 1983$;286 995-6.
}

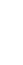
. 